\title{
Reseña de Texto
}

\section{Saggio sulla storia civile del Chili. Giovanni Ignazio Molina}

Alberto Trivero. Mondoví - Italia.

No hace mucho tiempo apareció en el mercado anticuario italiano un libro extremadamente raro e interesante para el mundo chileno y, particularmente lo mapuche. Se trata de la primera edición del «Saggio sulla storia civile del Chilì), del jesuita Giovanni Ignazio Molina, publicado en Bologna en el año 1787. Son muchos los elementos que hacen particularmente interesante a este libro: ilustra la visión que se tenía en Europa acerca del mundo mapuche hacia el final del siglo XVIII. Aunque tiene algo más de dos siglos de vida, sigue siendo una lectura muy interesante y fundamentalmente correcta. Tan sólo ocho años más tarde hubo una traducción y una edición española (Madrid 1795), dado que el autor, aunque de origen castellano, escribió su obra en italiano, y la traducción madrileña no siempre es fiel al texto, sino que a menudo lo altera voluntariamente, por las razones que ilustraremos.

El libro se presenta bien encuadernado en cuero, su tamaño es de $12 \times 19 \mathrm{~cm}$, y tiene 334 páginas. Posee una única ilustración: se trata de un mapa del territorio de la Araucanía que, como se explica en la introducción, ha sido impreso con una lastra de final del siglo XVII, pues desde entonces nunca se hicieron mapas de mejor calidad. Efectivamente ese mapa es excelente y muy atractivo: mide $40 \times 54 \mathrm{~cm}$ y es notablemente preciso. El texto se divide en cuatro libros y se completa con una gramática del mapudungun, un amplio diccionario con casi 50 formas verbales y una bibliografía.

Pero lo que hace más precioso el libro es su texto y la personalidad del autor.

Se trata de la segunda obra de Juan Ignacio Molina acerca de Chile, siendo la primera el «Saggio sulla storia naturale del Chile». En su obra el Autor no se basa en su conocimiento directo de los hechos. En lo que concierne a la historia más antigua, su referencia fundamental es un manuscrito del Abate Olivares «che ho presso di me, ed altre relazioni stampate mi fornivano $i$ materiali necessarj per condurre la mia Opera sino all'anno 1655 (que está en mi poder, y otras relaciones impresas que meàseguran los materiales necesarios para llevar mi obra hasta el año 1655 - pág. 3)». Lo que hace más interesante la lectura, es lo que se refiere a la historia más reciente, y sobre por todo cuanto es relativo a las costumbres mapuches. El se basa sobre los relatos de quienes han vivido en Chile, interrogando «molti de" miei compatriotti, soggiornanti quì in Italia, si ricordano tuttavia de' principali avvenimenti onde, mediante il loro ajuto, posso darne un ragguaglio sufficiente (muchos de mis compatriotas que habitan aquí en Italia, sin embargo se acuerdan de los principales acontecimientos, de tal manera que con su ayuda puedo dar una información suficiente - pag:4)».

Juan Ignacio Molina no se limita a referir los que sus testigos le cuentan sino que compara y analiza sus palabras, en cuanto «l'unico merito che ambisco, è quello di essere imparziale (el sólo merecimiento que ambiciono es aquello de ser imparcial - pag.4)». Y aquí tenemos la clave para leer esta obra: el intento de describir los hechos sin prejuicios y sin defender tesis preconcebidas.

Desde el punto de vista del estilo, la lectura del Saggio sulla storia civile del Chili es muy agradable e inesperada. El texto es muy simple y fluido, con períodos cortos, casi 'periodísticos', sin que aparezca ninguno de aquellos discursos eruditos e inútiles que hacen tan pesados los textos del siglo barroco. De la lectura se revela también la admiración enorme que el autor siente hacia el pueblo mapuche, que solamente pudo derivar de la misma admiración de la que daban muestras sus informantes. Justamente es esto lo que retrasó la publicación de su libro y, cuando finalmente aparece en Madrid ocho años más tarde, el texto está inevitablemente alterado, pues en el mundo español no podía admitirse tanta admiración por un pueblo que los conquis- 
tadores, después de dos siglos, todavía no podían derrotar.

Gran parte del 1er libro y todo el 2 do están dedicados a describir a los mapuches y sus costumbres. Los hombres son de bonito y noble aspecto y «alla vantaggiosa costituzione de' loro corpi corrisponde l'indole de'loro animi. Sono intrepidi, animosi, arditi, costanti nelle fatiche della guerra, prodighi della loro vita, quando si tratta del bene della patria, amanti soprammodo della libertà, che stimano come un costitutivo essenziale della loro esistenza, gelosi del proprio onore, accorti, ospitali, fedeli ne' contratti, riconoscenti de'benefizj, generosi, e umani verso $i$ vinti (a la provechosa constitución de sus cuerpos corresponde la índole de sus ánimos. Son intrépidos, animosos, valientes, constantes en los esfuerzos de la guerra, generosos en dar su vida cuando se trata del bien de la patria, amantes antes que todo de la libertad que consideran como una componente esencial de su existencia, celosos de su honor, diestros, hospitalarios, fieles en los empeños, agradecidos frente a los beneficios, generosos y humanitarios frente a los vencidos - pag. 54)». Los comandantes españoles, al contrario, a menudo son señalados por su crueldad, por su escasa fidelidad y por su cobardía: «agli Spagnuoli diedero sul bel principio il soprannome di Ciapi, cioè Soldati vigliacchi. [...] Di poi li chiamarono Huinca: questa maligna denominazione, che coll'uso, e col tempo ha perduto la sua odiosità, viene dal verbo huincun, che significa assassinare (a los españoles les dieron desde el primer momento el apodo de chapos, es decir soldados cobardes. Sucesivamente los 1lamaron huinca: este apodo maligno, que con el uso y con el tiempo ha perdido su odiosidad, deriva del verbo huincun que significa asesinar - pag. 103)».

En el siglo XVUI la falta de ciudades era estimada como prueba de salvajismo. Pero J. I. Molina no cae en este error, sino interpreta muy correctamente que «l'indole di questo Popolo altiero [...] non saprebbe adattarsi ad abitare dentro a Città murate, le quali esso riguarda come un contrassegno de servitù. Siccome la libertà è l'unico oggetto della sua ambizione, così crede, non senza ragione, di poterla conservar meglio, dimorando all'aperta Campagna (la índole de este Pueblo orgulloso no sabría adaptarse para vivir al interior de ciudades amuralladas, las que él considera como un símbolo de servidumbre. Así como la libertad es el único objeto de su ambición, ellos creen, con razón, que pueden conservarla mejor viviendo en el campo - pag. 57)».

El jesuita aprecia mucho el aspecto civil de su modo de vivir y de la organización social muy libertaria donde «l'autorità di questi Capi fosse assai limitata, cioè soltanto direttiva, e non coattiva, come è stata quella di tutti $i$ condottieri delle nazioni barbare (la autoridad de sus jefes es muy limitada, siendo solamente directiva y no coercitiva como lo es aquella de todos los caudillos de las naciones bárbaras - pag. 23)». Y luego remarca como del «vicendevole amore, che regna tra di loro, deriva la premura, che hanno nel soccorrersi ne' loro reciproci bisogni. Non si vede in tutto il loro Stato verun pezzente, o stracciato. Anche i più invalidi vanno decentemente vestiti. La loro beneficienza non si limita a' soli compatriotti. Estendesi all'ospitalità la più preveniente verso tutti i forestieri di qualsivoglia nazione. Un viandante può albergarvi da pertutto senza alcuna spesa (recíproco cariño que reina entre ellos deriva la atención que tienen en socorrerse en sus necesidades recíprocas. En todo su Estado no se ve ningún mendigo o andrajoso. Hasta los más inválidos andan decentemente arreglados. Su generosidad se extiende en la forma más previsora hacia todos los forasteros de cualquiera nacionalidad. Un viajero puede alojar en cualquier lugar sin ningún gasto - pag. 104). Es importante remarcar cómo el autor se refiere a la Araucanía utilizando el término de 'Estado', lo cual no podía claramente ser aceptado por la monarquía española.

También el Autor admira su limpieza y amor por el aseo: «E' singolare l'attenzione, che queste donne hanno per la pulizia. Spazzano le loro case, e i loro cortili molte volte al giorno. Appena hanno adoperato qualche arnese, che subito lo nettano, o lo lavano. [...] La medesima pulitezza usano verso sestesse. [...] Ne' loro abiti non si vede mai la menoma macchia, o lordura. Gli uomini ancora sono egualmente amanti della mondezza, si pettinano indispensabilmente tutti $i$ 
giorni, e usano anche di lavarsi la testa (Es singular el cuidado que estas mujeres tienen para la limpieza. Barren sus casas y sus patios muchas veces cada día. No apenas han utilizado alguna herramienta, la limpian o la lavan. La misma limpieza la vuelven hacia si mismas. En sus vestimentas nunca se ve una pequeña mancha 0 suciedad. Los hombres son igualmente amantes de la

- limpieza, se peinan sin falta cada día y también acostumbran lavarse su cabeza - pag. 108)».

También se destaca que «se l'educazione fisica de' Fanciulli araucani è in certo modo lodevole, l'educazione morale che si da a' medesimi [...] è conforme alle idee, che quell'indomito Popolo si è formato intorno all'innata libertà dell'Uomo, e quale si può aspettare da una gente non dirozzata (si la educación física de los niños es en cierta medida loable, la educación moral que viene dada a los mismos es conforme a las ideas que aquel indómito pueblo se ha formado acerca de la libertad del hombre, tal como nos podemos esperar de una gente no tosca - pag. 210)»>.

Analizando su religión, J. I. Molina mantiene su proposición de ser imparcial. Pues habla con respeto de su divinidad suprema, Pillán, y no cae en el error, frecuente en esos tiempos, de definirlo como 'ser demoníaco'. Celebra sus profundos conocimientos médicos (y también en este caso el Autor tiene muy clara la diferencia entre machi y kalku), de astronomía, y, por encima de todo, su afición al arte de la oratoria: «la rettorica specialmente è in grande stima presso di loro, perchè essa, come nell'antica Roma, conduce agli onori, e al maneggio degli affari. Il primogenito di un Ulmen, che non sappia arringare a dovere, viene per questa sola ragione escluso dalla sucessione paterna (muy especialmente entre ellos se estima la retórica, porque ella, como en la antigua Roma, conduce a los honores y a la gestión de los asuntos. El primogénito de un ulmen que no sepa expresarse como es conveniente, por esta sola razón puede ser excluido de la sucesión paterna - pag. 93).

El tercer y el cuarto libro son propiamente históricos. Pero el estilo es muy agradable y, contrariamente a los otros autores de la misma época, J. I. Molina trata cada acontecimiento ilustrando siempre cuanto se produce teniendo en consideración los dos sujetos de la confrontación, dando el mismo espacio al uno como al otro. Algunos errores históricos que están presentes, no comprometen la validez y la fiabilidad general del texto.

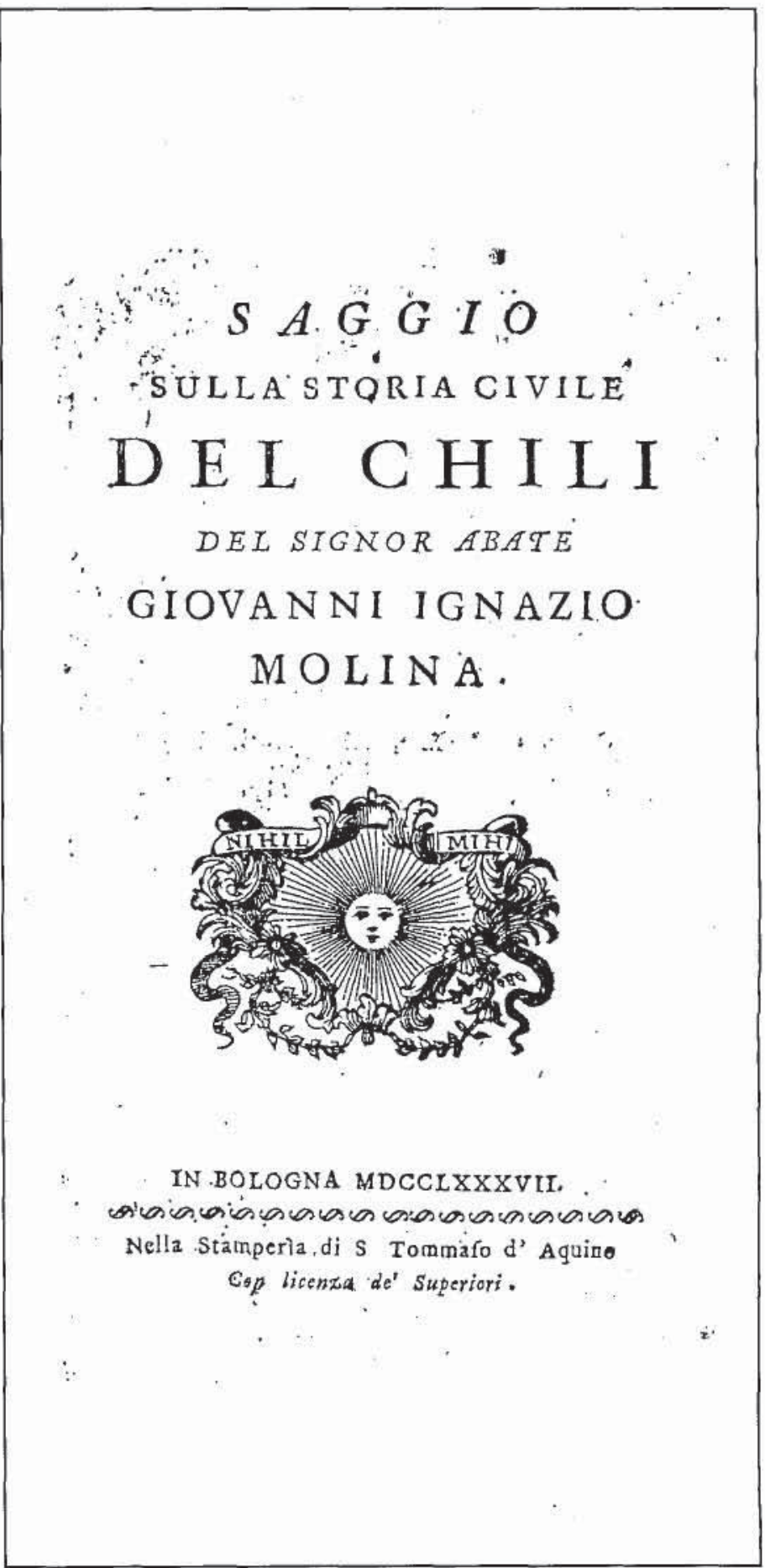

